\title{
Changes in inflammatory and oxidative stress factors and the protein synthesis pathway in injured skeletal muscle after contusion
}

\author{
XIAOGUANG LIU ${ }^{1}$, ZHIGANG ZENG ${ }^{1,2}$, LINLIN ZHAO ${ }^{1}$, WEIHUA XIAO ${ }^{1}$ and PEIJIE CHEN ${ }^{1}$ \\ ${ }^{1}$ School of Kinesiology, Shanghai University of Sport, Shanghai 200438; \\ ${ }^{2}$ College of Physical Education, Jinggangshan University, Ji'an, Jiangxi 343009, P.R. China
}

Received April 30, 2017; Accepted November 20, 2017

DOI: $10.3892 /$ etm.2017.5625

\begin{abstract}
Injury of skeletal muscle, and particularly mechanically-induced damage, including contusion injury, frequently occurs in contact sports as well as in sports with accidental contact. Although the mechanisms of skeletal muscle regeneration are well understood, those involved in muscle contusion are not. A total of 40 male mice were randomly divided into control $(n=8)$ and muscle contusion $(n=32)$ groups. A muscle contusion model was established by weight-drop injury. Subsequently, the gastrocnemius muscles in the two groups were harvested at different times (1, 3, 7 and 14 days) post-injury. The changes in skeletal muscle morphology were assessed by hematoxylin and eosin (H\&E) stains. Furthermore, quantitative polymerase chain reaction and western blotting were used to analyze inflammatory cytokines, oxidative stress factors and the Akt/mechanistic target of rapamycin (mTOR) pathway. The results revealed that pro-inflammatory cytokines [tumor necrosis factor- $\alpha$ (TNF- $\alpha$ ), interleukin-6 (IL-6) and interferon- $\gamma($ IFN- $\gamma$ ) increased significantly at day 1 and 3 and still exhibited high levels of expression at days 7 and 14 (except IL-6) post-injury. Additionally, the anti-inflammatory cytokine IL-10 increased significantly at 1,3 and 7 days and reached its peak levels at 7 days post-injury. It was revealed that gp91phox mRNA increased significantly at all time points and gp91phox protein increased significantly at day 3 post-injury. Furthermore, it was observed that $\mathrm{p}$-Akt/Akt increased significantly at 1 day post-injury. P-mTOR/mTOR increased significantly at day 1 and 7, and p-p70s6k/p70s6k and P-4EBP1/4EBP1 increased significantly at $1,3,7$ and 14 days post-injury. These results
\end{abstract}

Correspondence to: Dr Weihua Xiao or Dr Peijie Chen, School of Kinesiology, Shanghai University of Sport, 188 Hengren Road, Shanghai 200438, P.R. China

E-mail: xiaoweihua@sus.edu.cn

E-mail: chenpeijie@sus.edu.cn

Key words: muscle contusion, inflammatory factors, oxidative stress factors, Akt/mechanistic target of rapamycin pathway, muscle regeneration indicate that inflammatory and oxidative stress factors and the Akt/mTOR pathway may serve important roles in the regeneration of muscle contusion. In addition, certain inflammatory factors and oxidative stress factors maintained high levels of expression at 14 days after injury, indicating that the healing process of muscle was still not fully achieved at this time.

\section{Introduction}

Skeletal muscle injuries are common musculoskeletal problems encountered in sports medicine (1). In total, $>90 \%$ of muscle injuries are caused by contusion or by excessive strain of the muscle (2). Pain and restricted range of motion, due to these injuries, can lead to decreased performance and limited ability to play sports (3). Furthermore, repair of skeletal muscle injuries is regulated by multiple factors and can be divided into acute, repair and remodeling phases (4). The initial acute phase is characterized by concomitant hematoma formation, myofiber necrosis, degeneration and inflammatory response. The second phase, repair, consists of phagocytosis of the necrotized tissue and regeneration of the myofibers by activated and proliferating satellite cells. The final phase is characterized by the maturation of regenerated myofiber and scar tissue formation $(2,5,6)$.

Effective repair of injured muscle requires the coordinated action of several molecular, cellular and cell-signaling pathways $(5,6)$. Certain animal studies have revealed that the expression of inflammatory cytokines and oxidative stress factors were significantly increased following muscle injury and served an important role in the process of muscle regeneration $(7,8)$. Furthermore, protein synthesis signaling pathways were activated and served important roles in muscle regeneration $(9,10)$. As mentioned above, there is an appreciable understanding of the mechanisms of skeletal muscle regeneration. However, the understanding of this process has been limited to the injury models of disuse muscle atrophy (7), toxicant injection (11), freeze-induced injury (9) and mdx mice (12). The mechanisms of muscle regeneration involved in muscle contusion are still not fully understood. In addition, to the best of our knowledge, there is no systematic research on the inflammatory cytokines, oxidative stress factors and protein synthesis signaling pathways following muscle contusion. 
Therefore, in the present study, a skeletal muscle contusion model was constructed with the objective of exploring the mechanisms involved in muscle regeneration. The mRNA levels of inflammatory cytokines [including tumor necrosis factor- $\alpha$ (TNF- $\alpha$ ), interleukin-6 (IL-6), interferon- $\gamma$ (IFN- $\gamma$ ) and IL-10] and oxidative stress factors (gp91phox) were examined. Additionally, the protein levels of oxidative stress factors (gp91phox) were examined. The roles of the Akt/mTOR pathways were evaluated, which may be activated following muscle injury.

\section{Materials and methods}

Animals. In total, 40 C57BL/6 male mice (age, 8 weeks; weighing 18.2-22.9 g) purchased from Shanghai Lab, Animal Research Center (Shanghai, China) were housed at a constant temperature of $25^{\circ} \mathrm{C}$ and $\sim 50 \%$ relative humidity, with a light-dark cycle of 12:12 h, with free access to pellet food and water. A total of 8 mice were randomly selected for the uninjured control group $(n=8)$, while the rest $(n=32)$ were subjected to muscle contusion. Prior to contusion, the mice were anesthetized with $400 \mathrm{mg} / \mathrm{kg}$ chloral hydrate administered intraperitoneally. The study was approved by the Ethics Review Committee for Animal Experimentation of Shanghai University of Sport (Shanghai, China).

Contusion model. An animal model of muscle contusion was based on previously described studies $(2,13,14)$. The hind limb of the mouse was positioned by extending the knee and plantarflexing the ankle by $90^{\circ}$. A $16.8 \mathrm{~g}$ (diameter, $15.9 \mathrm{~mm}$ ) stainless steel ball was dropped from a height of $125 \mathrm{~cm}$ through a tube (interior diameter of tube, $16 \mathrm{~mm}$ ) onto an impactor (1), resting with a surface of $28.26 \mathrm{~mm}^{2}$ on the middle of the gastrocnemius muscle (GM) of the mice. The muscle contusion created by this method was a high-energy blunt injury that created a large hematoma and was followed by massive muscle regeneration $(13,15)$, a healing process that is very similar to those observed in humans $(16,17)$. Animals ( $n=8$ mice per time point) were sacrificed to harvest GMs at different time points (days 1, 3, 7 and 14) after injury.

Histology. At the time points of 1, 3, 7 and 14 days post-injury, the right GMs were collected and fixed with $4 \%$ paraformaldehyde for $15 \mathrm{~min}$ at room temperature and then embedded in paraffin. Muscle sections ( $8 \mu \mathrm{m}$ thick) were cut from the mid-belly region of GMs using a microtome (Leica-EG 1160, Leica Microsystems GmbH, Wetzlar, Germany). Sections were stained with hematoxylin for $5 \mathrm{~min}$ at room temperature and eosin for $3 \mathrm{~min}$ at room temperature (H\&E) for morphological analysis. Using a 20-lens objective, images were captured for each muscle section (Labophot 2, Nikon Corporation, Tokyo, Japan). Regenerating myofibers selected for analysis were centronucleated fibers (Labophot 2, Nikon Corporation, Tokyo, Japan), not bordering a fiber that was not centronucleated. Similarly, uninjured myofibers selected for analysis were non-centronucleated fibers that did not border a centronucleated fiber (Labophot 2, Nikon Corporation, Tokyo, Japan). The number of centronucleated and non-centronucleated fibers were evaluated by Image $\mathrm{J}$ 1.44 (National Institutes of Health, Bethesda, MD, USA).
Results were expressed as the mean \pm standard deviation (SD) with eight animals per group.

RNA extraction and cDNA synthesis. In total, $\sim 60 \mathrm{mg}$ of GMs were homogenized using an Ultra-Turrax homogenizer (IKA Group, Staufen, Germany) in a solution of TRIzol reagent (cat no. 15596018; Invitrogen; Thermo Fisher Scientific, Inc., Waltham, MA, USA). The total RNA was isolated using a modified guanidinium isothiocyanate- $\mathrm{CsCl}$ method (18). Following standing for $10 \mathrm{~min}, 200 \mu \mathrm{l}$ of chloroform (cat no. 10006818; China National Pharmaceutical Group Chemical Reagent Co., Ltd., Beijing, China) was added and mixed thoroughly upside down and then centrifuged at $12,000 \mathrm{x}$ g for $15 \mathrm{~min}$ at $4^{\circ} \mathrm{C}$. A total of $500 \mu \mathrm{l}$ supernatant was then pipetted into a new RNase-free centrifuge tube. An equal volume of isopropanol (cat no. 40064360; China National Pharmaceutical Group Chemical Reagent Co., Ltd.) was then added to the centrifuge tube, which was inverted and mixed well and left to stand for $20 \mathrm{~min}$. The sample was then centrifuged at $12,000 \mathrm{x}$ g at $4^{\circ} \mathrm{C}$ for $10 \mathrm{~min}$ and the white feather-like precipitate was RNA. The precipitate was washed twice with 75\% alcohol (cat no. 10009218; China National Pharmaceutical Group Chemical Reagent Co., Ltd.) and then dissolved in $30 \mu \mathrm{l}$ DEPC water (cat no. B501005-0500; Sangon Biotech Co., Ltd., Shanghai, China). The concentration and purity were determined by measuring the absorbance at 260 and $280 \mathrm{~nm}$ with a spectrophotometer (NanoDrop 2000, Thermo Fisher Scientific, Inc., ). The total RNA was reverse-transcribed into cDNA using the Revertaid First Strand cDNA Synthesis kit from Fermentas (cat. no. K1622; Thermo Fisher Scientific, Inc.). cDNA was synthesized using $2 \mu \mathrm{g}$ total RNA, $0.2 \mu \mathrm{g}$ random primers, $20 \mathrm{mM}$ dNTP mix, $5 \mathrm{X}$ reaction buffer, 20 units RiboLock ${ }^{\mathrm{TM}}$ RNase inhibitor and 200 units Revertaid $^{\mathrm{TM}} \mathrm{M}-\mathrm{MuLV}$ reverse transcriptase in a total volume of $20 \mu \mathrm{l}$. The reaction was performed at $25^{\circ} \mathrm{C}$ for $5 \mathrm{~min}$, followed by another $60 \mathrm{~min}$ at $42^{\circ} \mathrm{C}$, and terminated by the deactivation of the enzyme at $70^{\circ} \mathrm{C}$ for $5 \mathrm{~min}$. Control reactions lacking either reverse transcriptase or template were included to assess carryover of genomic DNA and non-specific contamination (14).

Quantitative polymerase chain reaction ( $q P C R$ ). Quantitative PCR was performed in triplicate in reactions consisting of $12.5 \mu 1$ 2X Maxima SYBR Green/ROX qPCR Master mix (Thermo Fisher Scientific, Inc.), $1 \mu 1$ cDNA, nuclease-free water and $300 \mathrm{nM}$ of each primer. The primer sequences are listed in Table I. Amplifications were performed on a StepOnePlus PCR-Cycler (Thermo Fisher Scientific, Inc.) with the following parameters: Activation at $95^{\circ} \mathrm{C}$ for $10 \mathrm{~min}$, followed by 40 cycles of denaturation at $95^{\circ} \mathrm{C}$ for $15 \mathrm{sec}$ and annealing/extension at $60^{\circ} \mathrm{C}$ for $1 \mathrm{~min}$. The threshold cycle (the number of cycles to reach threshold of detection) was determined for each reaction, and the levels of the target mRNAs were quantified relative to the level of the housekeeping gene GAPDH using the $2^{-\Delta \Delta \mathrm{Cq}}$ method (19).

Western blotting. In total, $\sim 80 \mathrm{mg}$ of tissue (from the middle of the left GM) was homogenized in cold radioimmunoprecipitation assay buffer (Beyotime Institute of Biotechnology, Haimen, China) by an ultrasonic vibrator and a mechanical homogenizer. The protein concentration was determined by the bicinchoninic acid (BCA) method (BCA Protein Assay kit, 
Table I. Primer sequences for the quantitative polymerase chain reaction.

\begin{tabular}{lll}
\hline Target gene & \multicolumn{1}{c}{ Forward } & \multicolumn{1}{c}{ Reverse } \\
\hline TNF- $\alpha$ & 5'-CTTCTGTCTACTGAACTTCGGG-3' & 5'-CACTTGGTGGTTTGCTACGAC-3' \\
IFN- $\gamma$ & 5'-GCTTTGCAGCTCTTCCTCAT -3' & 5'-GTC ACC ATCCTTTTGCCAGT -3' \\
IL-6 & 5'-GAACAACGATGATGCACTTGC-3' & 5'-CTTCATGTACTCCAGGTAGCTATGGT-3' \\
IL-10 & 5'-CAAGGAGCATTTGAATTCCC-3' & 5'-GGCCTTGTAGACACCTTGGTC-3' \\
gp91phox & 5'-CCAGTGAAGATGTGTTCAGCT-3' & 5'-GCACAGCCAGTAGAAGTAGAT-3' \\
GAPDH & 5'-ACTCCACTCACGGCAAATTC-3' & 5'-TCTCCATGGTGGTGAAGACA-3' \\
\hline
\end{tabular}

TNF- $\alpha$, tumor necrosis factor- $\alpha$; IFN- $\gamma$, interferon- $\gamma$; IL-6, interleukin-6; IL-10, interleukin- 10 .

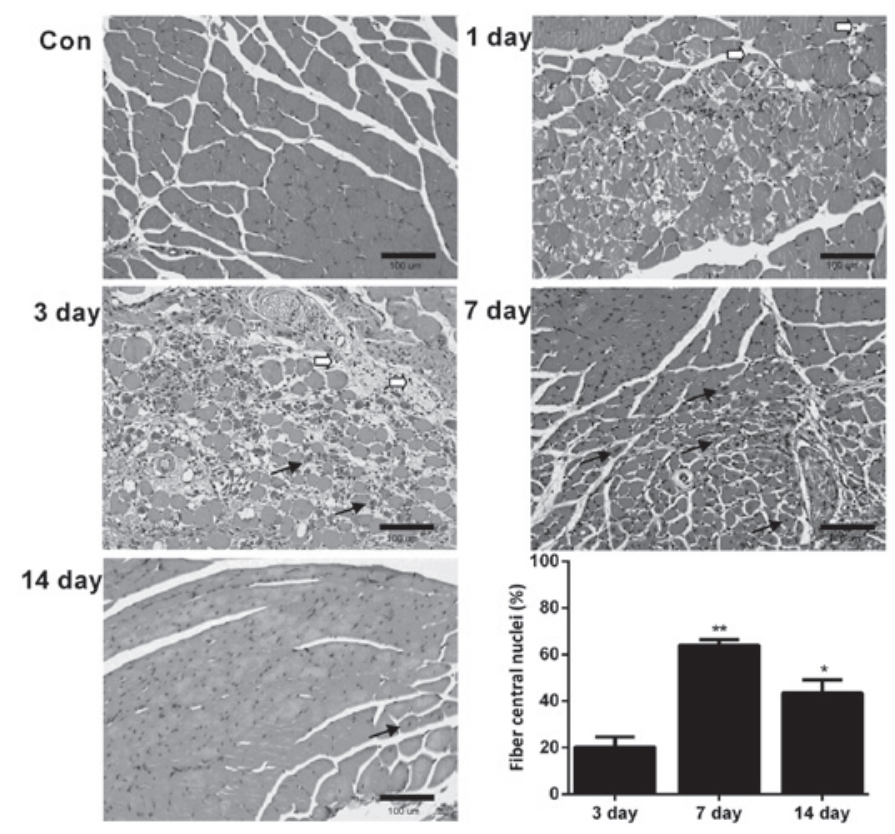

Figure 1. Histological evaluation of muscle regeneration following contusion injury by hematoxylin and eosin staining. Scale bars, $100 \mu \mathrm{m}$. White arrows indicate inflammatory cells; black arrows indicate centralized nuclei. Data are presented as the mean \pm standard deviation, $\mathrm{n}=8 ;{ }^{*} \mathrm{P}<0.05$ and ${ }^{* * *} \mathrm{P}<0.01$ vs. the 3 day group.

P0010, Beyotime Institute of Biotechnology). For the protein assay, the protein samples that contained an equal amount of protein $(30 \mu \mathrm{g})$ were electrophoresed on $8 \%$ SDS-PAGE gels and transferred onto PVDF membranes (EMD Millipore, Billerica, MA, USA). The membranes were blocked with 5\% non-fat milk powder in Tris-buffered saline Tween-20 buffer for $60 \mathrm{~min}$ at room temperature. Following blocking, the immunoblots were incubated with primary antibodies against NOX2/gp91phox (cat no. ab80508; 1:1,000; Abcam, Cambridge, UK), Akt (cat no. 4685; 1:1,000; Cell Signaling Technology, Inc., Danvers, MA, USA), phospho-Akt (cat no. 4060; 1:1,000; Cell Signaling Technology, Inc.), mTOR (cat no. 2983; 1:1,000; Cell Signaling Technology, Inc.), phospho-mTOR (cat no. 5536; 1:1,000; Cell Signaling Technology, Inc.), p70s6k (cat no. 2708; 1:1,000; Cell Signaling Technology, Inc.), phospho-p70s6k (cat no. 9234; 1:1,000; Cell Signaling Technology, Inc.), 4E-binding protein 1 (cat no. 9644; 4EBP1; 1:1,000; Cell Signaling Technology, Inc.), phospho-4EBP1 (cat no. 2855; 1:1,000; Cell Signaling Technology, Inc.) and GAPDH (cat no. 2118; 1:1,000; Cell Signaling Technology,
Inc.) at $4^{\circ} \mathrm{C}$ overnight, followed by incubation with a secondary horseradish peroxidase-conjugated $\operatorname{IgG}$ (cat no. sc-516087; 1:5,000; Santa Cruz Biotechnology, Inc., Dallas, TX, USA) for $1 \mathrm{~h}$ at room temperature. The results were visualized with the enhanced chemiluminescence method and were evaluated using Image J 1.44 (NIH, Bethesda, MD, USA).

Statistical analysis. Data are expressed as the mean \pm SD and were analyzed by one-way analysis of variance with the least significant difference method as a post-hoc test (SPSS 20.0; IBM Corp., Armonk, NY, USA). P<0.05 was considered to indicate a statistically significant difference.

\section{Results}

Muscle morphology. The H\&E results revealed that there was substantial fiber damage, edema and inflammatory cell infiltration 1 day after muscle injury. On day 3 post-injury, there were still a large number of inflammatory cells and necrotic muscle fibers. However, a small number of centronucleated 
A
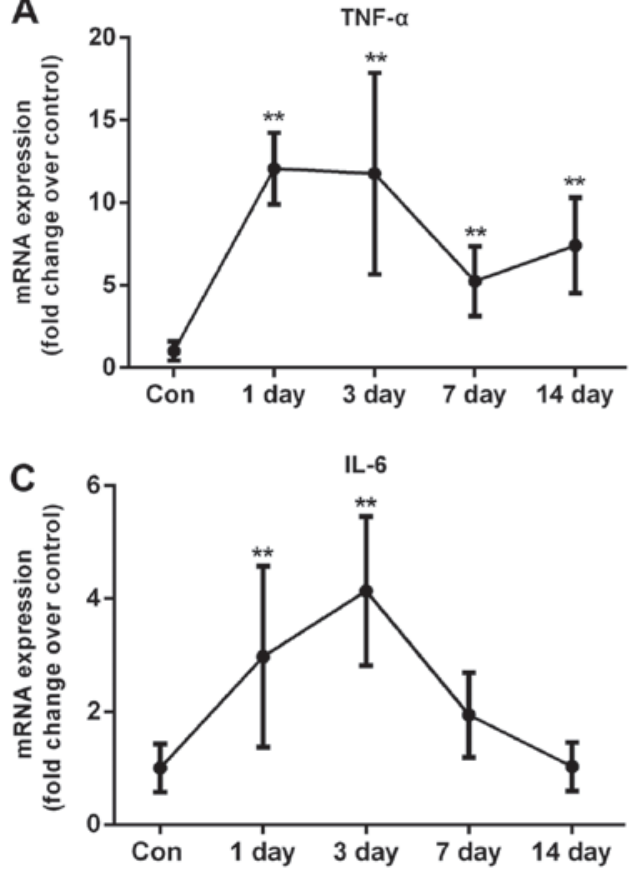

B

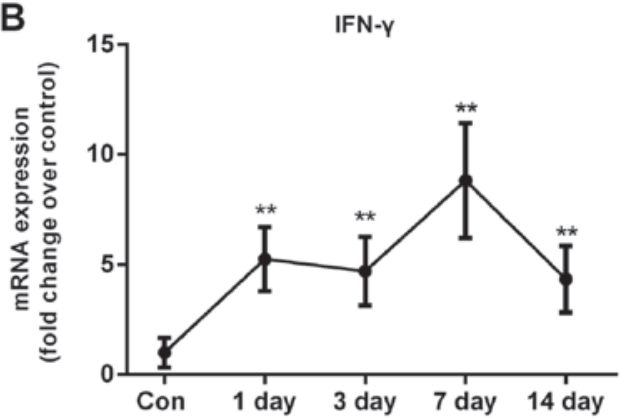

D

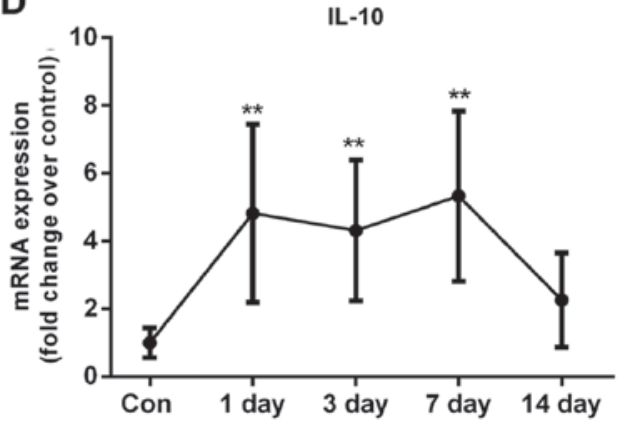

Figure 2. mRNA levels of inflammatory cytokines in skeletal muscle post-injury. (A) TNF- $\alpha$, (B) IFN- $\gamma$, (C) IL-6 and (D) IL-10. Data are presented as the mean \pm standard deviation, $\mathrm{n}=8 ;{ }^{* *} \mathrm{P}<0.01$ vs. the control group. TNF- $\alpha$, tumor necrosis factor- $\alpha$; IFN- $\gamma$, interferon- $\gamma ;$ IL- 6 , interleukin- 6 ; IL-10, interleukin-10.

myofibers were observed 3 days post-injury. At 7 days after injury, the damaged muscle area had been replaced mostly by centronucleated muscle fibers. At 14 days post-injury, there was still a small number of centronucleated muscle fibers. Morphometric analysis, using quantitative stereology, confirmed that at $7(\mathrm{P}<0.01)$ and 14 days $(\mathrm{P}<0.01)$ after injury, the percentage of the centronucleated myofibers had increased significantly compared with 3 days post-injury (Fig. 1).

Inflammatory cytokine levels. The expression of inflammatory cytokines (TNF- $\alpha$, IFN- $\gamma$, IL-6 and IL-10) was studied. TNF- $\alpha$ mRNA increased significantly at 1 (12.05-fold), 3 (11.75-fold), 7 (5.24-fold) and 14 days (7.41-fold) in skeletal muscle post-injury compared with the control (all $\mathrm{P}<0.01$; Fig. 2A). IFN- $\gamma$ mRNA increased significantly at all-time points $1,3,7$ and 14 days post-injury compared with the control (all $\mathrm{P}<0.01$; Fig. 2B). In addition, it was observed that IL-6 mRNA expression increased significantly at 1 (2.97-fold) and 3 days (4.14-fold) post-injury compared with the control $(\mathrm{P}<0.01$; Fig. $2 \mathrm{C})$. The mRNA expression of IL-10 (anti-inflammatory cytokine) significantly increased at 1 and 3 days $(\mathrm{P}<0.01)$, peaked at 7 days $(5.33$-fold; $\mathrm{P}<0.01)$ compared with the control (Fig. 2D).

Nicotinamide adenine dinucleotide phosphate (NADPH) oxidase levels. The mRNA levels of gp91phox, which is the key subunit of NADPH oxidases, were evaluated. The results of the present study demonstrated that gp91phox mRNA levels significantly increased at the time points of $1,3,7$ and 14 days, and peaked 3 days after injury compared with the control $(\mathrm{P}<0.01$; Fig. 3). In addition, the protein levels of the gp91phox were examined using western blotting. The protein levels of gp91phox also increased significantly compared with the control at 3 days post-injury ( $\mathrm{P}<0.01$; Fig. 4).

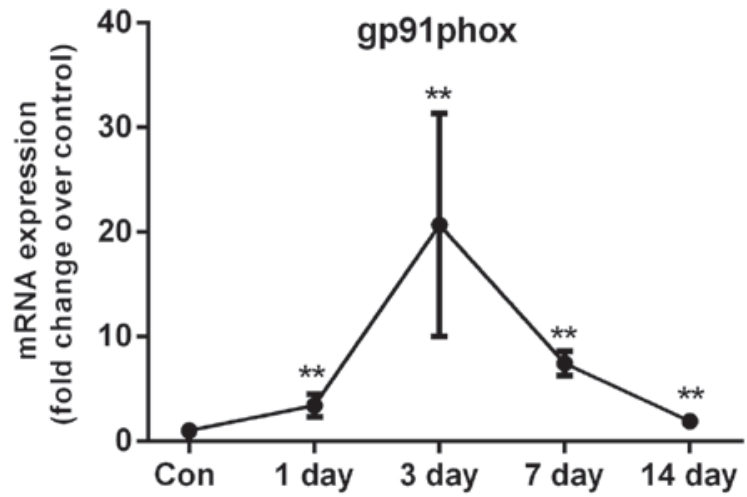

Figure 3. mRNA levels of gp91phox in skeletal muscle post-injury. Data are presented as the mean \pm standard deviation, $n=8 ;{ }^{* *} \mathrm{P}<0.01$ vs. the group.

Akt/mTOR pathway. The Akt/mTOR pathway, which is involved in skeletal muscle regeneration post-injury, was evaluated (Fig. 5). Western blot analysis revealed that p-Akt/Akt increased significantly at 1 day post-injury compared with the control ( $\mathrm{P}<0.01 ;$ Fig. 5A). p-mTOR/mTOR increased significantly at $1(\mathrm{P}<0.01)$ and 7 days $(\mathrm{P}<0.05)$ post-injury compared with the control (Fig. 5B). However, p-p70s6k/p70s6k expression increased significantly compared with the control group at all time points post-injury $(\mathrm{P}<0.01$ at day $1, \mathrm{P}<0.05$ at days 3,7 and 14 ; Fig. 5C). Similarly, P-4EBP1/4EBP1 increased significantly at all time points post-injury compared with the control group $(\mathrm{P}<0.01$; Fig. 5D).

\section{Discussion}

Inflammatory responses are integral components of the host's reaction to muscle injury, and the inflammatory cytokines serve 

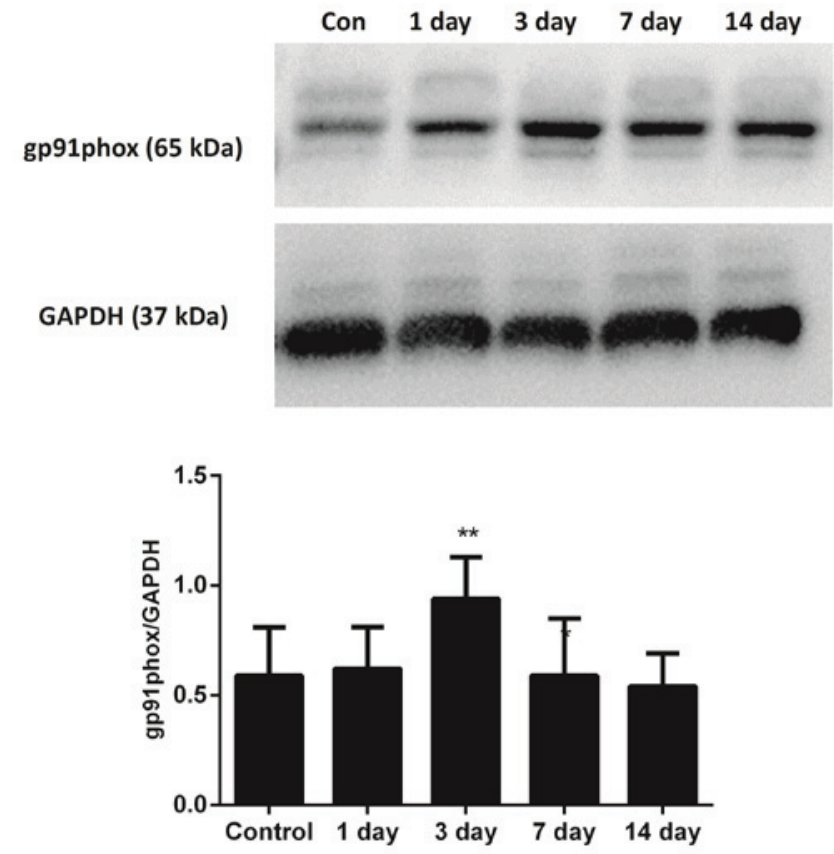

Figure 4. Protein levels of gp91phox in skeletal muscle post-injury. Data are presented as the mean \pm standard deviation, $n=8 ;{ }^{* *} \mathrm{P}<0.01$ vs. the uninjured control group.

crucial roles in subsequent muscle regeneration (20). TNF- $\alpha$ serves an essential role in the cytokine cascade by stimulating IL-6 secretion. This has pro- and anti-inflammatory effects and is frequently used as a marker of systemic pro-inflammatory activation (21). Experimental evidence has also indicated that TNF- $\alpha$ can influence muscle repair and regeneration by modulating the proliferation and differentiation of satellite cells in injured tissue (6). In addition, Warren et al (22) revealed that TNF- $\alpha$ mRNA was increased to the maximum at $24 \mathrm{~h}$ and returned to the control levels by day 13 after injury. The expression of IL-6 mRNA was similar to TNF- $\alpha$ (22). Furthermore, the results of the present study were similar to the study by Warren et al (22). It was revealed that the level of TNF- $\alpha$ mRNA peaked 1 day post-injury. On the other hand, there were some differences between the two studies. It was demonstrated that there was still high expression of TNF- $\alpha$ mRNA at 7 and 14 days post-injury. Additionally, it was identified that IL-6 mRNA significantly increased at 1 day and peaked at 3 days post-injury. The reason for the disparity may be associated with the different models of muscle injury and the different muscles in the two studies.

IFN- $\gamma$, another inflammatory cytokine, is a powerful activator of neutrophils and the M1 macrophage (23). Furthermore, IFN- $\gamma$ stimulation can enhance the responsiveness of neutrophils to chemotactic cytokines, thereby potentially increasing their invasion into injury sites. Thus, the elevated levels of IFN- $\gamma$ expression that accompany acute muscle injuries possess the potential to amplify the innate immune response, and potentially exacerbate muscle damage that occurs during the early inflammatory response (6). In addition, Cheng et al (24) revealed that IFN- $\gamma$ mRNA expression was barely evident in uninjured control muscle but increased substantially following injury, peaking at 5 days post-injury. The results of the present study were similar to the study by Cheng et al (24), however, in the present study IFN- $\gamma$ mRNA still exhibited high expression compared with the control group at 14 days post-injury.

Additionally, the anti-inflammatory cytokine IL-10 was studied, which serves a central role in regulating the switch of macrophages from an M1 to an M2 phenotype in injured muscle $(5,7)$. Ablation of IL-10 expression in mdx mice increased muscle damage in vivo and reduced muscle strength (25). Furthermore, IL-10 was predominantly expressed in the later stage of regeneration, limiting inflammation and promoting muscle regeneration (26). Similar to other studies, the present study revealed that pro-inflammatory cytokines (TNF- $\alpha$, IFN- $\gamma$ and IL-6) increased significantly at an early stage of muscle regeneration (1-3 days), and decreased progressively (except IFN- $\gamma$ ) in the later stage (7-14 days), with IL-10 being predominantly expressed at 7 days post-injury compared with the control group. This result was consistent with the study by Deng et al (7), which revealed that injured muscle is characterized by high levels of expression of TNF- $\alpha$, CC-chemokine ligand 2 and IL- 6 at 1 day post-injury. During the later stage of muscle regeneration, expression of those transcripts declined while the IL-10 and IL-10 receptor-1 increased (7). On the other hand, the current study indicated that there were still high levels of expression of TNF- $\alpha$ and IFN $-\gamma$ mRNA in the later stages of muscle regeneration ( 7 and 14 days) compared with the control group. However, our previous study demonstrated that TNF- $\alpha$ and IFN- $\gamma$ mRNA increased significantly at an early stage and returned to normal in the later stage of muscle regeneration (5). One of the possible reasons is that the muscle injury model in the present study was more severely damaged than the previous one (stainless steel ball was dropped from a height of $125 \mathrm{vs} .100 \mathrm{~cm}$ ).

NADPH oxidase is a major source of reactive oxygen species, which may be involved in the oxidative stress of skeletal muscle (27). Furthermore, NADPH oxidase of phagocytes is a multi-subunit complex consisting of three cytosolic subunits (p47phox, p67phox and p40phox), a G protein (Rac1 or Rac2) and two membrane-bound subunits p22phox and Nox2 (also known as gp91phox) $(28,29)$. In addition, gp91phox is the key subunit of NADPH oxidases, typically known as a marker of NADPH oxidases (8,29-31). A null mutation of gp91phox reduces the expression of NADPH oxidase and muscle membrane lysis during muscle inflammation in mice (32). Previous evidence indicates that gp91phox is increased significantly in tibilais anterior muscles from mdx mice compared with wild type, and enhanced NADPH oxidase activity contributes to muscle damage and functional impairment (33). In addition, Ghaly and Marsh (8) revealed that the gp91phox protein increased significantly at the time points of $8 \mathrm{~h}$ and 3 days post-injury. In the present study the results were similar to the study by Ghaly and Marsh (8), since the gp91phox protein increased significantly at 3 days post-injury.

The mRNA levels of gp91phox were examined by RT-qPCR. The data revealed that the gp91phox mRNA increased significantly at the time points of 1, 3, 7 and 14 days post-injury. These results indicate that the oxidative stress accompanied with muscle contusion may contribute to muscle injury $(33,34)$.

Several reports have demonstrated that the Akt/mTOR pathway is associated with muscle growth, hypertrophy and regeneration (35-37). Furthermore, activation of the Akt/mTOR 
A
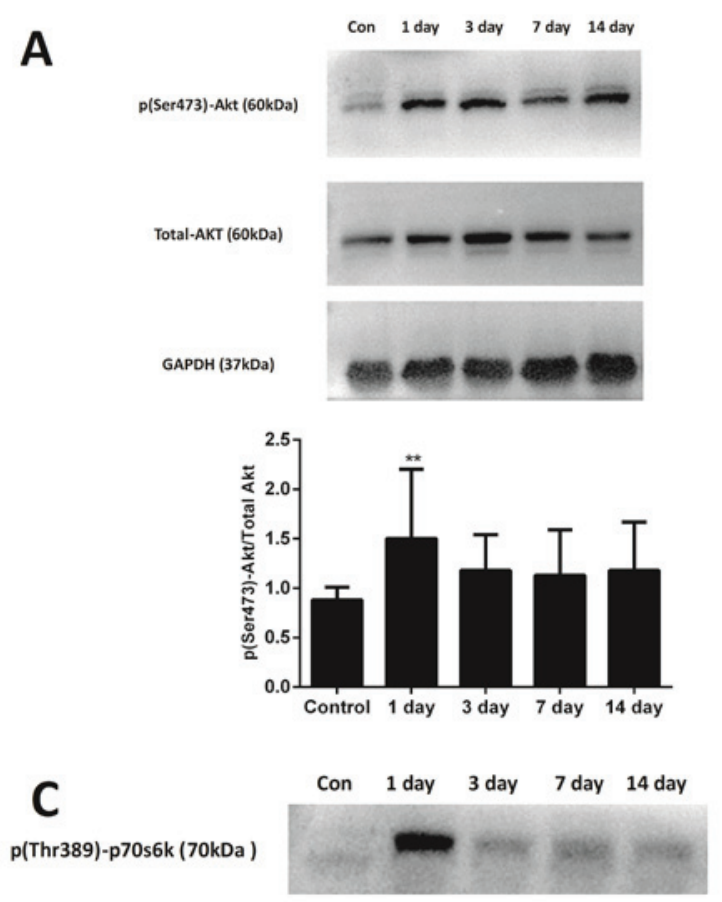

Total p70s6k (70kDa)

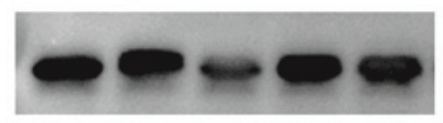

GAPDH (37kDa)
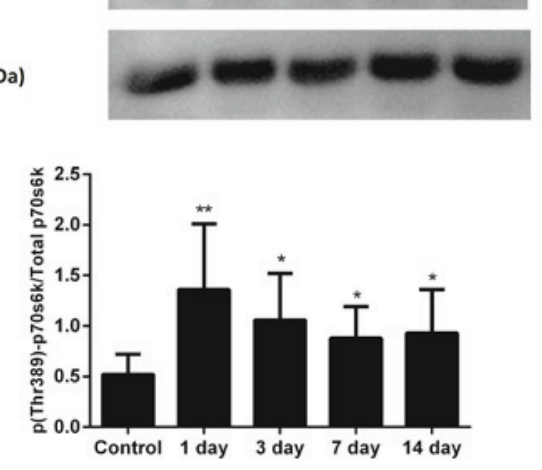

B

p(Ser2448)-mTOR (289kDa)

Con 1 day 3 day 7 day 14 day

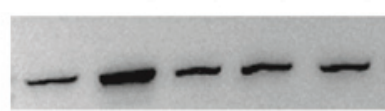

Total mTOR (289kDa)

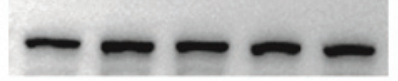

GAPDH (37kDa)
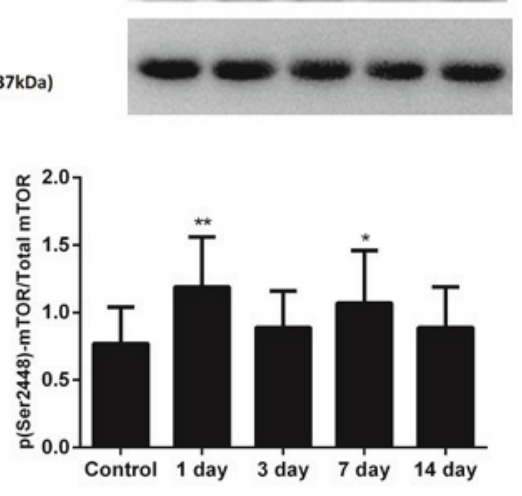

D

$\mathrm{p}(\mathrm{Thr} 37 / 46)-4 E B P 1$ (15-20 kDa)

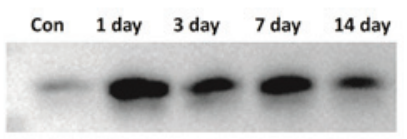

Total 4EBP1 (15-20 kDa)

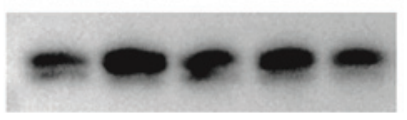

GAPDH (37kDa)
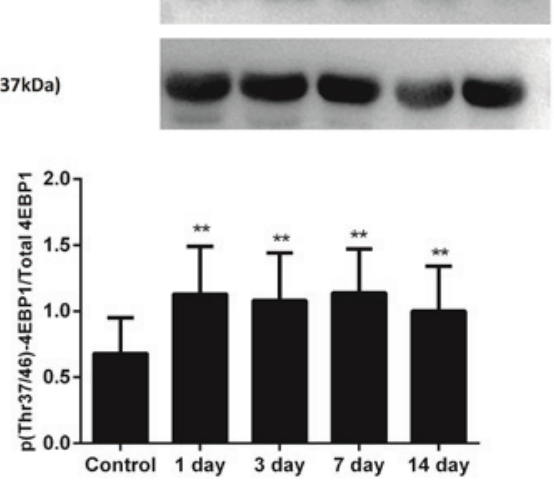

Figure 5. Expression of phosphorylated and total protein of (A) Akt, (B) mTOR, (C) p70s6k and (D) 4EBP1 in the muscle post-injury. Data are presented as the mean \pm standard deviation, $n=8 ;{ }^{*} \mathrm{P}<0.05$ and ${ }^{* *} \mathrm{P}<0.01$ vs. control group. mTOR, mechanistic target of rapamycin; 4EBP1, 4E-binding protein 1 .

pathway and its downstream targets, p70S6K and 4EBP1, is involved in regulating skeletal muscle fibre size, and activation of the Akt/mTOR pathway can oppose muscle atrophy induced by disuse (38). Upon tissue injury, the cues released by the inflammatory component of the regenerative environment instruct somatic stem cells to repair the damaged area (6). In addition, a large amount of protein synthesis is required in the process of muscle regeneration, and the Akt/mTOR pathway may be involved in this (39).

It was previously reported that the ratio of phosphorylated to native mTOR increased significantly at 10 days post-injury (10). Also, the ratio of phosphorylated to native p70s6k was reported to increase significantly 1 day post-cryolesion (9). Furthermore, the current study investigated the activation of the Akt/mTOR pathway and its downstream targets, p70S6K and 4EBP1, following muscle contusion. The results were similar with those of the studies mentioned above; the ratio of phosphorylated to native mTOR increased significantly at 7 days, and the ratio of phosphorylated to native p70s6k increased significantly at 1 day after muscle contusion. On the other hand, the data of the present study revealed that the ratio of phosphorylated to native Akt, mTOR, p70s6k and 4EBP1 increased significantly 1 day after muscle contusion compared to the control group. These results indicate that the activation of the Akt/mTOR pathway occurred on the first day following muscle contusion, and it may serve an important role in the process of muscle regeneration.

In conclusion, the upregulated expression of inflammatory and oxidative stress factors, and the Akt/mTOR pathway were activated in skeletal muscle following injury, and they may serve important roles in the regeneration of muscle contusion. Additionally, certain inflammatory and oxidative stress factors maintained high levels of expression 14 days after injury, indicating that the healing process of the injured muscle was still not fully completed at that time.

\section{Acknowledgements}

The present study was supported by grants from the National Natural Science Foundation of China (grant nos. 31271273 
and 31300975), the Doctoral Fund of Ministry of Education of China (grant no. 20133156120004) and the Key Lab of Exercise and Health Sciences of Ministry of Education (Shanghai University of Sport).

\section{References}

1. Ota S, Uehara K, Nozaki M, Kobayashi T, Terada S, Tobita K, $\mathrm{Fu}$ FH and Huard J: Intramuscular transplantation of muscle-derived stem cells accelerates skeletal muscle healing after contusion injury via enhancement of angiogenesis. Am J Sports Med 39: 1912-1922, 2011.

2. Wright-Carpenter T, Opolon P, Appell HJ, Meijer H, Wehling P and Mir LM: Treatment of muscle injuries by local administration of autologous conditioned serum: animal experiments using a muscle contusion model. Int J Sports Med 25: 582-587, 2004.

3. Delos D, Leineweber MJ, Chaudhury S, Alzoobaee S, Gao Y and Rodeo SA: The effect of platelet-rich plasma on muscle contusion healing in a rat model. Am J Sports Med 42: 2067-2074, 2014.

4. Zhang M, Jiang SK, Tian ZL, Wang M, Zhao R, Wang LL, Li SS, Liu M, Li JY, Zhang MZ and Guan DW: CB2R orchestrates fibrogenesis through regulation of inflammatory response during the repair of skeletal muscle contusion. Int J Clin Exp Pathol 8 3491-3502, 2015.

5. Xiao W, Liu Y, Luo B and Chen P: Time-dependent gene expression analysis after mouse skeletal muscle contusion. J Sport Health Sci 5: 101-108, 2016.

6. Tidball JG: Mechanisms of muscle injury, repair, and regeneration. Compr Physiol 1: 2029-2062, 2011

7. Deng B, Wehling-Henricks M, Villalta SA, Wang $\mathrm{Y}$ and Tidball JG: IL-10 triggers changes in macrophage phenotype that promote muscle growth and regeneration. J Immunol 189 3669-3680, 2012.

8. Ghaly A and Marsh DR: Aging-associated oxidative stress modulates the acute inflammatory response in skeletal muscle after contusion injury. Exp Gerontol 45: 381-388, 2010.

9. Miyabara EH, Conte TC, Silva MT, Baptista IL, Bueno C Jr, Fiamoncini J, Lambertucci RH, Serra CS, Brum PC, Pithon-Curi T, et al: Mammalian target of rapamycin complex 1 is involved in differentiation of regenerating myofibers in vivo. Muscle Nerve 42: 778-787, 2010.

10. Conte TC, Silva LH, Silva MT, Hirabara SM, Oliveira AC, Curi R, Moriscot AS, Aoki MS and Miyabara EH: The $\beta 2$-adrenoceptor agonist formoterol improves structural and functional regenerative capacity of skeletal muscles from aged rat at the early stages of postinjury. J Gerontol A Biol Sci Med Sci 67: 443-455, 2012.

11. Zhang P, Liang X, Shan T, Jiang Q, Deng C, Zheng R and Kuang S: mTOR is necessary for proper satellite cell activity and skeletal muscle regeneration. Biochem Biophys Res Commun 463: 102-108, 2015.

12. Bobadilla M, Sáinz N, Rodriguez JA, Abizanda G, Orbe J, de Martino A, García Verdugo JM, Páramo JA, Prósper F and Pérez-Ruiz A: MMP-10 is required for efficient muscle regeneration in mouse models of injury and muscular dystrophy. Stem Cells 32: 447-461, 2014.

13. Kasemkijwattana C, Menetrey J, Somogyl G, Moreland MS, Fu FH, Buranapanitkit B, Watkins SC and Huard J: Development of approaches to improve the healing following muscle contusion. Cell Transplant 7: 585-598, 1998.

14. Xiao W, Liu Y and Chen P: Macrophage depletion impairs skeletal muscle regeneration: the roles of Pro-fibrotic factors, inflammation, and oxidative stress. Inflammation 39: 2016-2028, 2016.

15. Crisco JJ, Jok1 P, Heinen GT, Connell MD and Panjabi MM: A muscle contusion injury model. Biomechanics, physiology and histology. Am J Sports Med 22: 702-710, 1994.

16. Diaz JA, Fischer DA, Rettig AC, Davis TJ and Shelbourne KD: Severe quadriceps muscle contusions in athletes. A report of three cases. Am J Sports Med 31: 289-293, 2003.

17. Li H, Chen J, Chen S, Zhang Q and Chen S: Antifibrotic effects of Smad4 small interfering RNAs in injured skeletal muscle after acute contusion. Int J Sports Med 32: 735-742, 2011.

18. Chirgwin JM, Przybyla AE, MacDonald RJ and Rutter WJ: Isolation of biologically active ribonucleic acid from sources enriched in ribonuclease. Biochemistry 18: 5294-5299, 1979.

19. Livak KJ and Schmittgen TD: Analysis of relative gene expression data using real-time quantitative PCR and the 2(-Delta Delta C(T)) method. Methods 25: 402-408, 2001.
20. Zhang C, Li Y, Wu Y, Wang L, Wang $\mathrm{X}$ and Du J: Interleukin-6/signal transducer and activator of transcription 3 (STAT3) pathway is essential for macrophage infiltration and myoblast proliferation during muscle regeneration. J Biol Chem 288: 1489-1499, 2013.

21. Lima AA, Spinola LG, Baccan G, Correia K, Oliva M, Vasconcelos JF, Soares MB, Reis SR and Medrado AP: Evaluation of corticosterone and IL-1 $\beta$, IL-6, IL-10 and TNF- $\alpha$ expression after 670-nm laser photobiomodulation in rats. Lasers Med Sci 29: 709-715, 2014

22. Warren GL, Hulderman T, Jensen N, McKinstry M, Mishra M, Luster MI and Simeonova PP: Physiological role of tumor necrosis factor alpha in traumatic muscle injury. FASEB J 16: 1630-1632, 2002

23. Villalta SA, Deng B, Rinaldi C, Wehling-Henricks $M$ and Tidball JG: IFN- $\gamma$ promotes muscle damage in the $\mathrm{mdx}$ mouse model of Duchenne muscular dystrophy by suppressing M2 macrophage activation and inhibiting muscle cell proliferation. J Immunol 187: 5419-5428, 2011.

24. Cheng M, Nguyen MH, Fantuzzi G and Koh TJ: Endogenous interferon-gamma is required for efficient skeletal muscle regeneration. Am J Physiol Cell Physiol 294: C1183-C1191, 2008.

25. Villalta SA, Rinaldi C, Deng B, Liu G, Fedor B and Tidball JG: Interleukin-10 reduces the pathology of mdx muscular dystrophy by deactivating M1 macrophages and modulating macrophage phenotype. Hum Mol Genet 20: 790-805, 2011.

26. Tidball JG and Villalta SA: Regulatory interactions between muscle and the immune system during muscle regeneration. Am J Physiol Regul Integr Comp Physiol 298: R1173-R1187, 2010.

27. Xiao W, Chen P, Wang R and Dong J: Overload training inhibits phagocytosis and ROS generation of peritoneal macrophages: Role of IGF-1 and MGF. Eur J Appl Physiol 113: 117-125, 2013.

28. Babior BM: NADPH oxidase: An update. Blood 93: 1464-1476, 1999.

29. Chan EC, Jiang F, Peshavariya HM and Dusting GJ: Regulation of cell proliferation by NADPH oxidase-mediated signaling: Potential roles in tissue repair, regenerative medicine and tissue engineering. Pharmacol Ther 122: 97-108, 2009.

30. Ghaly A and Marsh DR: Ischaemia-reperfusion modulates inflammation and fibrosis of skeletal muscle after contusion injury. Int J Exp Pathol 91: 244-255, 2010.

31. Zhang Q, Wang Y, Man L, Zhu Z, Bai X, Wei S, Liu Y, Liu M, Wang X, Gu X and Wang Y: Reactive oxygen species generated from skeletal muscles are required for gecko tail regeneration. Sci Rep 6: 20752, 2016.

32. Nguyen HX and Tidball JG: Null mutation of gp91phox reduces muscle membrane lysis during muscle inflammation in mice. J Physiol 553: 833-841, 2003.

33. Whitehead NP, Yeung EW, Froehner SC and Allen DG: Skeletal muscle NADPH oxidase is increased and triggers stretch-induced damage in the mdx mouse. PLoS One 5: e15354, 2010.

34. Kozakowska M, Pietraszek-Gremplewicz K, Jozkowicz A and Dulak J: The role of oxidative stress in skeletal muscle injury and regeneration: Focus on antioxidant enzymes. J Muscle Res Cell Motil 36: 377-393, 2015.

35. Rommel C, Bodine SC, Clarke BA, Rossman R, Nunez L, Stitt TN, Yancopoulos GD and Glass DJ: Mediation of IGF-1-induced skeletal myotube hypertrophy by $\mathrm{PI}(3) \mathrm{K} / \mathrm{Akt} / \mathrm{mTOR}$ and $\mathrm{PI}(3)$ K/Akt/GSK3 pathways. Nat Cell Biol 3: 1009-1013, 2001.

36. Boppart MD, Burkin DJ and Kaufman SJ: Activation of AKT signaling promotes cell growth and survival in a7 $\beta 1$ integrin-mediated alleviation of muscular dystrophy. Biochim Biophys Acta 1812: 439-446, 2011.

37. Laplante M and Sabatini DM: mTOR signaling in growth control and disease. Cell 149: 274-293, 2012.

38. Bodine SC, Stitt TN, Gonzalez M, Kline WO, Stover GL, Bauerlein R, Zlotchenko E, Scrimgeour A, Lawrence JC, Glass DJ and Yancopoulos GD: Akt/mTOR pathway is a crucial regulator of skeletal muscle hypertrophy and can prevent muscle atrophy in vivo. Nat Cell Biol 3: 1014-1019, 2001.

39. Li HY, Zhang QG, Chen JW, Chen SQ and Chen SY: The fibrotic role of phosphatidylinositol-3-kinase/Akt pathway in injured skeletal muscle after acute contusion. Int J Sports Med 34: 789-794, 2013. 